\title{
Relações de gênero e orientação sexual no currículo da disciplina de Ensino Religioso em escolas estaduais e municipais de Recife
}

\section{Gender relations and sexual orientation in Religious Education curriculum in state and municipal schools in Recife}

Aurenéa Maria de Oliveira*

\begin{abstract}
Resumo
Esta pesquisa realizada em escolas públicas estaduais e municipais de Recife em Pernambuco por meio de projeto de iniciação científica que contou com o apoio da UFPE e do CNPq teve como objetivo, analisar no currículo da disciplina de Ensino Religioso (ER), o lugar que mulheres, especialmente as com orientação sexual marginalizada como lésbicas, bissexuais e transexuais, ocupam. Para tal, trabalhamos com a metodologia da Análise de Discurso e com a Teoria do Discurso, procurando primeiro, identificar as principais ideologias que cercavam e envolviam o tema, para em seguida, localizar o discurso hegemônico ou os discursos hegemônicos que se afirmavam ao redor dele. Sendo assim, chegou-se à conclusão que abordagens sobre religião, gênero e diversidade sexual, que são expressas no cotidiano das salas de aula, não são, no entanto, levantadas no componente disciplinar examinado devido à ausência de um currículo que possa auxiliar docentes por meio de atividades propostas e conteúdos pragmáticos que estimulem o surgimento de pontos a serem considerados, negociados e correlacionados às temáticas em questão. Sendo assim, as dificuldades em se dialogar acerca da orientação sexual e homossexualidade de modo geral, e especificamente, no caso feminino, são grandes na disciplina de ER nas escolas pesquisadas.
\end{abstract}

Palavras-chave: Ensino Religioso; Gênero; Orientação Sexual; Currículo.

\begin{abstract}
This research conducted in state and municipal public schools of Recife in Pernambuco through research project that had the support of UFPE and CNPq aimed to analyze the Religious Education curriculum (ER), the place that women, especially with marginalized sexual orientation as lesbian, bisexual and transgender occupy. To this end, we work with the methodology of Discourse Analysis and the Theory of Speech, looking first identify the main ideologies surrounding and involving the theme, then locate the hegemonic discourse or hegemonic discourses that claimed around him. Thus, it reached the conclusion that approaches religion, gender and sexual diversity, which are expressed in the daily life of the classrooms are not, however, raised the disciplinary component examined in the absence of a curriculum that can assist teachers by through proposals and pragmatic content activities that encourage the emergence of points to be considered, negotiated and correlated to the themes in question. Thus, the difficulties in dialogue about sexual orientation and homosexuality in general, and specifically in the female case, are great in ER discipline in the schools surveyed.
\end{abstract}

Keywords: Religious Education; gender; sexual orientation; Curriculum.

Artigo recebido em 20 de abril de 2015 e aprovado em 17 de setembro de 2015.

* Doutora em Sociologia e mestre em Ciência Política (UFPE), licenciada em História (UFRPE) e professora adjunta III, no Departamento de Fundamentos Sócio-Filosóficos da Educação, e no PPGE da UFPE. País de origem: Brasil. E-mail: aurenea@hotmail.com

Horizonte, Belo Horizonte, v. 13, n. 39, p. 1510-1533, jul./set. 2015 - ISSN 2175-5841 


\section{Introdução}

Os dados de violência apresentados pelo estado de Pernambuco nas últimas décadas chamam a atenção posto que, de acordo com o DataSUS (Departamento de Informática do Sistema Único de Saúde do Brasil) no período de 1979 a 2002, por exemplo, 4.798 mulheres foram assassinadas (SOS CORPO - PESQUISA, 2014). Esse número triplicou entre os anos de 1979 a 2000 tendo em vista que no final da década de 70 foram registrados 94 casos e em 2000 foram registrados 309 (SOS CORPO - PESQUISA, acessado em 28/04/2014). Como podemos observar, essas são estatísticas referentes apenas aos homicídios, que são os casos mais graves, sem levar em consideração as ocorrências de agressão física, estupros e ameaças de morte, e eles, não refletem a realidade devido ao fato das mulheres terem medo de denunciar seus agressores. Assim, mesmo com todo aparato legal e de segurança que uma cidade como Recife oferece, sabe-se que ainda muitas mulheres não prestam queixas quando são agredidas.

Todos esses dados corroboraram com a constatação feita pelo IBGE no ano de 2000, de que Pernambuco foi o estado que apresentou a mais alta taxa de homicídio, ganhando naquele ano o título, nada honroso, de estado brasileiro mais

violento (IBGE, 2000, acessado em 2013). Evidentemente que essa violência não se resume só aos crimes contra as mulheres, contudo, o problema da violência é muito grave quando se sublinham os números elevados de crimes praticados contra o sexo feminino, pois estes potencializam a violência sexista, homofóbica, revelando processos de intolerância e exclusão.

Assim é que reforçando esse argumento, dados expostos pelo SOS Corpo, advindos da Secretaria de Defesa Social de PE (SDS), e que se referem aos homicídios femininos ocorridos em Pernambuco no período de 2001 a 2003, atestam que em 2001, 293 casos foram registrados, em 2002, 369 e em 2003, 300 crimes foram contabilizados (SOS CORPO - PESQUISA, 2014). Entre 2002 e 2004 a imprensa noticiou 355 homicídios femininos e a SDS divulgou mais 167 
casos, totalizando 528 (SOS CORPO - PESQUISA, 2014). Diante disso, esses números atestam a necessidade de se debruçar sobre esse fenômeno, investigando sobre as possíveis causas e alternativas de soluções que possam ser implementadas para conter esse tipo específico de violência contra as mulheres.

Mais especificamente, dentre esses casos de mulheres, vítimas de agressão, intolerância e de exclusão, acredita-se ser de suma relevância investigar o caso das que são marginalizadas sexualmente, posto que a associação homofobia e machismo potencializa os casos de violência, tendo em vista, entre outros fatores e apesar de alguns avanços, a tímida presença do setor judiciário neste tipo de discussão.

Wânia Izumino (1998) chama a atenção para o fato de que de uma maneira geral, no Brasil, o sistema judiciário tem dificuldades em criminalizar a violência contra a mulher à medida que em nossa sociedade, uma vez que as agressões praticadas contra elas ocorrem na maior parte das vezes no âmbito das relações íntimas, privadas e interpessoais, não são por conta disso, socialmente elaboradas e reconhecidas como crime.

Assim, se existe uma dificuldade em se punir a violência contra a mulher concebida como "legítima", imagine se punir as agressões e crimes contras aquelas tidas socialmente como "ilegítimas". Assim, é que os agressores, assassinos das mulheres reconhecidas como as "do lar" são ainda muitas vezes protegidos pela famosa tese do crime em defesa da honra, crime que segundo Caulfield (2000), os advogados e juízes liberais no Brasil no século XIX não conseguiram frear, por conta dos conceitos de honra e de moralidade que permaneceram no código penal, favorecendo fundamentos para privilégios patriarcais como o da defesa da virgindade e o da fidelidade feminina (CAULFIELD, 2000). Com relação a lésbicas, bissexuais e transexuais a situação agrava-se posto que, suas orientações sexuais sendo concebidas como deturpações, são comumente associadas ao pecado, à impureza, ao nojento e à sujeira, o que estimula representações de repulsa sobre 
elas, expressando uma das faces - que se quer eliminar - da cidade doente.

Igualmente às profissionais do sexo, vinculadas através do discurso médico do século XIX e aos textos legais do Brasil Império, à imagem da vadiagem, mendicância e alcoolismo (ENGEL, 2004), essas mulheres, ao não se comportarem segundo a lógica heteronormativa, vêem seus corpos serem alçados a condição de abjetos, colocados na esfera da desordem moral e social que necessita ser banida. Esses significados que perpassaram as falas de médicos, políticos, advogados e juízes no século XIX sobre a prostituição, ainda existem ressignificados nos dias de hoje, justificando atitudes de intolerância, preconceito e violência física e/ou verbal contra aquelas que se desviam dos padrões sexualmente aceitos. No Brasil, essa situação das lésbicas, bissexuais e transexuais igualmente emerge “... vinculada às desigualdades de gênero, que colocam as mulheres em uma posição de grande desvantagem em relação aos homens" (PORTELLA, 2003, p. 63).

Desse modo, ante esse cenário, esta pesquisa teve como objetivo analisar, através do currículo de Ensino Religioso (ER) e de entrevistas que foram realizadas com técnicos de educação, professores e gestores de escolas da rede pública municipal e estadual de Recife no estado Pernambuco, o lugar que mulheres sexualmente e socialmente marginalizadas como as citadas lésbicas, bissexuais e transexuais, ocupam dentro das principais cosmologias religiosas, com o fim de verificar se atitudes de intolerância e/ou não, são estimuladas contra elas a partir da relação estabelecida nesta disciplina de ER entre religião, gênero e diversidade/ diferença sexual.

A presença da disciplina de ER nas escolas, sobretudo públicas, é um assunto que provoca debates a favor e contra entre representantes da área de educação, das religiões, do governo e da sociedade como um todo (OLIVEIRA; SILVA, 2012). Um dos eixos dessa discussão é o da laicidade do estado brasileiro, isto é, a concepção de que os órgãos públicos assumem o compromisso de serem neutros em questões de consciência e liberdade religiosas, se contrapondo à catequese e à defesa de alguma 
religião. Por esse entendimento e também por ter o ER uma longa história de proselitismo no Brasil, a disciplina iria, especialmente para seus oponentes, de encontro à laicização nos espaços públicos, incluído entre esses espaços, a escola (OLIVEIRA; SILVA, 2012).

No entanto, do outro lado, existem os discordantes dessa visão que afirmam que o ER não deve ser concebido como ensino das religiões, não correspondendo a práticas de catequese ou ao ensino de alguma religião, mas sim, a busca pelo conhecimento da pluralidade religiosa, para o respeito e tolerância entre as várias denominações religiosas existentes no país, especialmente neste momento em que a atual LDB/1996 estabelece o combate aos preconceitos, estigmas e intolerância religiosa nas determinações do ER (OLIVEIRA et al, 2013).

Em Pernambuco, o ER é respaldado pela Instrução Normativa $n^{0} 01 / 2012$; pela Resolução $\mathrm{CEB} / \mathrm{CNE} \mathrm{n}^{0} 7 / 2010$ e pela Lei de diretrizes e Bases da Educação (LDB 9.394/ 96) que o concebem de matrícula facultativa, sendo parte integrante da formação básica do cidadão, assegurando-lhe o respeito à diversidade cultural religiosa brasileira, pois, são vedadas quaisquer formas de proselitismo (fé/religião) e constrangimento, tanto junto aos com religião como aos sem religião e ateus (INSTRUÇÃO NORMATIVA DE PERNAMBUCO n no 01/2012/ SECRETARIA DE EDUCAÇÃO DO ESTADO DE PERNAMBUCO, 2013). Mas, é fato que mesmo com a determinação de ensino não proselitista, o que se observa é que o ER, pelo menos nas escolas públicas de Pernambuco, vem sendo dado de modo híbrido, isto é, misturando elementos de catequese a leituras mais contemporâneas de compreensão da disciplina (OLIVEIRA, 2013).

Em tal contexto pergunta-se: como as questões sobre gênero e diversidade sexual e/ou orientação sexual, que de acordo com atual LDB, se colocam para serem trabalhadas pelas diferentes disciplinas como temas transversais, adotando uma postura de respeito às diferenças, são trabalhadas no currículo de ER? Como lidar com o machismo presente em muitas das cosmologias religiosas, sobretudo as 
mais tradicionais? Indo mais além, como segmentos socialmente e sexualmente marginalizados como mulheres lésbicas, bissexuais e transexuais são tratadas nessa/por essa disciplina? Sobre a relação sexo e religião, Endsjo (2014) escreve no prefácio de seu livro:

Ao adentrarmos o jardim sagrado do sexo e da religião, logo nos deparamos com uma quantidade incontável de variantes. Ao mesmo tempo que adolescentes cristãs vão a bailes de castidade nos quais prometem a Deus abstinência de sexo até o casamento, existem monges budistas que consideram o sexo entre homens um mistério sagrado. Não há uma abordagem simples à relação sexo e religião. Debates religiosos sobre a homossexualidade dominam as manchetes dos jornais e fiéis especulam se a pena de morte deveria ser a punição para certas formas de heterossexualidade, se a promiscuidade é a causa de furacões e do holocausto nuclear, se Deus condena o casamento de pessoas de diferentes crenças e se existe sexo no paraíso (ENDSJO, 2014, p. 4).

Esta relação complicada entre sexo e religião que cita o autor e que perpassa a história da humanidade, possui, contudo, abordagens distintas a partir da cosmologia das diferentes crenças. Correlacionando essa temática a questões de gênero, pode-se perceber, no entanto, que independentemente das diversas visões de mundo religiosas, em boa parte delas, a mulher ocupa lugar e função de submissão (ENDSJO, 2014, p. 517) 1 .

Pernambuco ocupa no momento o $10^{\circ}$ lugar no ranking dos estados mais violentos contra mulheres no Brasil (SOS CORPO - PESQUISA, 2014). Esta violência reitera-se, torna-se mais contundente e evidente quando atrelada ao estigma advindo de ser lésbica, bissexual e ou transexual, pois, nestes casos, o estado passa de $10^{\circ}$ ao $2^{\circ}$ lugar no ranking nacional (ONG GRUPO LEÕES DO NORTE, 2014). Sendo assim, entendemos que essas ações agressivas ocorrem por um desequilíbrio das relações de gênero e também por diversas formas de desigualdades

\footnotetext{
${ }^{1}$ Aqui é relevante colocar que discursos/posturas contra-hegemônicos, que rejeitam esse lugar de submissão feminina, existem dentro de várias cosmologias religiosas. Citemos como exemplo o fato de termos pastoras na tradição luterano-cristã. Outro fato, que merece ser sublinhado, diz respeito à importância de se ter certos cuidados quando lidarmos com as diversas cosmovisões religiosas e as relações de gênero estabelecidas dentro delas, situando-as em seu tempo e espaço, evitando com isso incorrer em anacronismos.
} 
que se manifestam na sociedade, potencializando a violência sexista e homofóbica, aliada à intolerância e exclusão. Tais atitudes atingem diversos setores da sociedade pernambucana e estão presentes na escola sob formas variadas (violência física e simbólica) produto de uma cultura masculina dominante (LIMA; OLIVEIRA, 2014).

Alguns estudos realizados sobre o currículo mostraram que não existe uma preocupação com as discussões sobre gênero e diversidade e/ou orientação sexual entre muitas disciplinas, isso numa perspectiva socialmente construída (sociocultural) defendida por pós-estruturalistas ou pós-fundacionistas como Judith Butler, por exemplo, que sublinha segundo Louro (2001) a: “... incapacidade de coerência da identidade de gênero, que, se pensada em uma estrutura binária e linear, pressupõe uma necessidade de ajuste à norma por parte daqueles que não se enquadram em tais estruturas" (LOURO, 2001, p. 5).

Outro fator importante sinalizado neste debate é o de que as discussões de gênero e sexualidade são apenas identificadas nas disciplinas de Ciências, atravessadas por lógicas biológicas positivistas, de valorização do corpo físico em detrimento das relações construídas sócio/culturalmente (LOURO, 2001, p. 5).

Diante disso, constatou-se a necessidade de analisar como a disciplina de ER vem se comportando em tal cenário, levando em consideração nesse processo como nas escolas estaduais e municipais de Recife ela vem elaborando procedimentos teórico-metodológicos de seleção de conteúdo programático e de ensinoaprendizagem e a correlação dessa seleção e procedimentos a questões vinculadas à religião, ao gênero e à diversidade e/ou orientação sexual. Uma de nossas metas neste sentido foi a de promover a discussão sobre a disciplina, enfatizando concepções de pluralidade, tolerância e alteridade no sentido de conter a violência praticada contra mulheres que não seguem os padrões heteronormativos, 
sexualmente adotados pela maioria².

\section{Aporte Teórico/Metodológico}

Adotando uma abordagem qualitativa, a pesquisa de título "Pluralismo, alteridade e relações de gênero: problematizando o debate nas escolas estaduais e municipais de Recife acerca do lugar que a mulher ocupa no currículo da disciplina de Ensino Religioso" buscou entender o ser humano dentro de contextos socioculturais. Tal compreensão levou a escolha pelo trabalho metodológico com a Análise de Discurso (AD) desenvolvida por Michel Pêcheux em sua terceira fase, e o exame teórico/interpretativo à abordagem da Teoria do Discurso (TD) elaborada por Ernesto Laclau e Chantal Mouffe. Desse modo, esses autores forneceram o suporte teórico/metodológico, auxiliando na identificação de ideologias presentes nos discursos que expressam, nesta perspectiva, relações de lugar e sentido em se tratando do status que mulheres sexualmente marginalizadas ocupam dentro das cosmologias religiosas trabalhadas na disciplina de Ensino Religioso em escolas públicas de Recife.

Ela foi realizada de agosto de 2013 a julho de 2014, na UFPE (Universidade Federal de Pernambuco), Centro de Educação, com o auxílio de bolsa de iniciação científica, fornecida pelo CNPq. O universo de busca acadêmica envolveu discursos e conceitos sobre: políticas curriculares, cultura, hibridismo, gênero, sexualidade, preconceito, estigma, tolerância/intolerância e diferença. A pesquisa de campo se deu em 02 escolas estaduais de Recife e 02 escolas municipais de Recife, num total

\footnotetext{
2 Neste aspecto, faz-se importante ressaltar que a discussão sobre o tema transversal do gênero e da orientação sexual não deve ficar circunscrita à disciplina de Ensino Religioso. Optou-se por seu trato aqui devido à relação negativa que as esferas "sexo e religião" assumem muitas vezes em nossa sociedade. Neste sentido, visando estabelecer um recorte, foi que o debate foi enfatizado na recepção dessas temáticas (gênero e sexualidade) neste componente curricular, do que sobre os estudos histórico-escolares sobre o Ensino Religioso no Brasil. Sobre essas questões, há muitos estudos que podem ser encontrados e consultados, entre outros autores, através das produções de Sérgio Rogério Azevedo Junqueira e do Grupo de Pesquisa Educação e Religião (GPER), na Pontifícia Universidade Católica do Paraná.
} 
de 04 estabelecimentos, além de visitas às secretarias de educação que representam o estado de PE e o município da capital pernambucana.

Como instrumento de trabalho, fizemos uso de entrevistas semiestruturadas com professores, gestores e técnicos das secretarias municipais e estaduais de Recife com o intuito de relacionar os discursos e ideologias presentes nas falas dos entrevistados, a sentidos circulantes, que na perspectiva metodológica da $\mathrm{AD}$, expressam memórias e produção de significados no social (ORLANDI, 2002).

A partir das entrevistas e transcrições, localizamos as ideologias atuantes nos discursos dos entrevistados usando os recursos da $\mathrm{AD}$. A interpretação do social, feita através da TD, buscou evidenciar processos significativos de articulação que culminam ou não, em discursos hegemônicos em torno de sentidos difundidos pela disciplina de ER no terreno especifico da diversidade sexual e/ou orientação sexual, enfocada dentro das falas sobre gênero (LACLAU; MOUFFE, 1985).

Assim, concordando com ORLANDI (2002), procurou-se através da AD “... compreender a língua fazendo sentido, enquanto trabalho simbólico, parte do trabalho social geral, constitutivo do homem e de sua história" (ORLANDI, 2002, p.15) e, por meio da TD, localizar percepções hegemônicas envolvendo as relações entre sexualidade, diversidade e religião no campo do discurso curricular da disciplina de ER.

Desse modo, objetivou-se compreender esses processos primeiro, através de discursos, estes entendidos não somente como falas e sim igualmente como práticas, pois são responsáveis pela elaboração de significação e ação no social (LACLAU; MOUFFE, 1985) e segundo, pela avaliação do currículo de ER, currículo este concebido como uma elaboração cotidiana feita dentro e fora das escolas (LOPES, 2004). 
Assim, o trabalho possibilitou sinalizar para discursos que são legitimados, em detrimento de outros que são negados no processo de desconstrução/reconstrução da disciplina de ER no contexto contemporâneo em Pernambuco.

A discussão sobre tolerância/intolerância foi um dos pontos fortes na avaliação das entrevistas. Neste aspecto, a pesquisa apoiou-se na perspectiva de que por ser um conceito em construção, a tolerância se compromete a não exprimir uma atitude de abnegação ou compaixão, e sim o respeito ao direito que o outro possui de ser e pensar diferente de nós (OLIVEIRA, 2006; 2007).

De acordo com Robert Paul Wolf (1970), em texto clássico, nas democracias pluralistas, surgidas na América moderna como a canadense e a norte-americana, por exemplo, a virtude é a tolerância. Apesar de sua crítica ao ideal de tolerância desenvolvido nos EUA, no que se refere a sua presença no campo político, afirma que ela é a "... condição da sociedade que permite à democracia formular bem e concretizar o ideal de pluralismo" (WOLFF; BARRINGTON; MARCUSE, 1970, p. 22)

Assim, associando o pluralismo à tolerância, destaca três diferentes tipos de justificação para esta junção: a primeira, mais antiga, do período pré-industrial, advinda dos conflitos religiosos entre católicos e protestantes, não-conformistas e anglicanos defendia que "... a tolerância de práticas religiosas divergentes constitui um mal necessário, imposto a uma sociedade que não pode suprimir a dissidência ou julga excessivamente altos os custos sociais da repressão" (WOLFF; BARRINGTON; MARCUSE, 1970, p. 22 e 23); a segunda justificação apresenta-se como "... meio moralmente neutro de perseguir fins políticos que não se podem alcançar através da democracia representativa tradicional. Segundo essa versão, o ideal da democracia é o Estado de cidadãos, no qual o homem faz suas leis e a elas se submete" (WOLFF; BARRINGTON; MARCUSE, 1970, p. 23). 
A partir dessa última justificativa, é justa a ordem política em que o povo, na extensão do indivíduo e de sua organização em grupos, desempenha um papel significativo e não apenas simbólico no processo de tomada de decisões políticas; tais decisões, porém, são tomadas por instâncias democráticas que visam encontrar meios para que os governantes se submetam às vontades dos governados, fazendo emergir o pluralismo e a tolerância - esta última expressada, sobretudo através da esfera política que ao defender a diversidade, absorve as pressões da sociedade estabelecendo o equilíbrio entre os grupos, pois vai acomodando suas demandas no Estado pluralista - como soluções (WOLFF; BARRINGTON; MARCUSE, 1970, p. 23 e 24). Assim a pressão entre grupos é vista como algo extremamente salutar ao ambiente democrático (OLIVEIRA, 2006).

A terceira justificativa, advinda da associação entre pluralismo e tolerância, sustenta que a sociedade pluralista sendo natural e boa, possibilita ao indivíduo construir lealdades múltiplas de grupos intra-sociais "... nos quais os homens mantêm os contatos diretos que lhes sustentam a personalidade e lhes reforçam as atitudes-valores" (WOLFF; BARRINGTON; MARCUSE, 1970, p. 26). De acordo com esses autores, a cada defesa do pluralismo, temos uma defesa da tolerância, com ela sendo na primeira defesa um mal necessário, exigida, no entanto pela voz da razão, para freiar as paixões da fé intolerante; na segunda, expressando a capacidade de aceitar reivindicações concorrentes como legítimas, reconhecendo o direito à promoção de direitos opostos; e na terceira, como sendo algo salutar para o desenvolvimento sadio do indivíduo à medida que a multiciplicidade de grupos lhe beneficia afetiva e emocionalmente (WOLFF; BARRINGTON; MARCUSE, 1970, p. 28 e 29).

É nesta última acepção que entendemos a tolerância tendo em vista que, não sendo esta uma expressão altruísta de caridade que no fundo rejeita a diferença, ela, no entanto, pauta-se pela noção de positividade da pluralidade. Neste aspecto,a diferença deixa de ser compreendida como algo negativo, passando a ser vislumbrada em sua complexidade e riqueza (OLIVEIRA, 2006; 2007). 
Ainda neste aspecto, evita-se cair nas armadilhas do estigma e da intolerância na medida em que tanto um quanto outro expressam/revelam a dificuldade no trato com o não semelhante, o não igual. Segundo Goffman (1963), quando somos formados por pré-concepcões sociais que nos inclinam para expectativas normativas, que caso não sejam correspondidas pelo outro promove mal estar, se estabelece uma crise que se apóia numa falta de sincronia entre a identidade social virtual - que é a esperada socialmente - e a identidade social real que é a apresentada pelo outro concretamente (GOFFMAN, 1963, p. 12). Essa falta de sincronia por sua vez, pode levar ao preconceito e este ao estigma e à intolerância, sobretudo nas sociedades tradicionais modernas que afirmaram as suas identidades pela semelhança e não pela diferença (OLIVEIRA, 2006; 2007); sobre isso afirma Goffman (1963):

Em primeiro lugar, há as abominações do corpo - as várias deformidades físicas. Em segundo lugar, as culpas de caráter individual, percebidas como vontade fraca, paixões tirânicas ou não naturais, crenças falsas e rígidas, desonestidade, sendo essas inferidas a partir de relatos conhecidos de, por exemplo, distúrbio mental, prisão, vício, alcoolismo, homossexualismo, desemprego, tentativas de suicídio e comportamento político radical. Finalmente, há os estigmas tribais de raça, nação e religião. (GOFFMAN, 1963, p. 14).

Do estigma para a intolerância, a fronteira é tênue, posto que a passagem de uma atitude de rejeição/não aceitação para a de agressão, seja física ou simbólica, reflete no mínimo dificuldades danosas socialmente, no que tange ao tratamento com a dessemelhança do outro. Neste aspecto, discutindo sobre a tolerância e a intolerância, comenta Cardoso (2003), a partir de Bobbio:

Existem a tolerância e a intolerância boas e a tolerância e a intolerância ruins. Elas formam pares opostos de valores de forma cruzada, ou seja, a tolerância boa opõe-se à intolerância ruim e a intolerância boa opõe-se à tolerância ruim. Vejamos. Quando defendemos os valores da liberdade, respeito às diferenças culturais e convivência pacífica, estamos nos referindo à tolerância em sentido positivo e rejeitando atitudes de preconceito e de todas as formas de exclusão do diferente que constituem a intolerância em sentido negativo. Por sua vez, a tolerância negativa 
veicula sentidos de indiferença diante do outro, condescendência ante o erro, indulgência com a opressão, tudo em nome de uma tranqüilidade de vida descompromissada. A denúncia desta e a sua oposição significam defender a intolerância em sentido positivo: aquela que revela a firmeza nos princípios, isto é, que defende a justa exclusão de tudo aquilo que provoca opressão e desigualdades sociais (CARDOSO, 2003, p. 164 e 165).

Neste aspecto, é que nesta pesquisa o trato com esses dois conceitos perpassou pela ideia de que tolerar não implica nem em aceitar tudo, nem em tratar como inimigo aquele que diverge de mim. Neste aspecto, sem negar o potencial conflitivo das relações, a tolerância aqui passa pela noção de alteridade, isto é, de diálogo que parte do pressuposto da não concordância como algo salutar (OLIVEIRA, 2008).

\section{Resultados}

Dando seguimento ao proposto acima nos objetivos do trabalho, abaixo segue um quadro que expõe alguns dados dos entrevistados destacados, tendo em vista que auxiliaram no processo de análise. É interessante informar que como a pesquisa não envolveu crianças, nem adolescentes, não necessitou de parecer de Comissão de Ética da UFPE, instituição que a apoiou. Contudo, para preservar a identidade dos entrevistados, não foram mencionados seus respectivos nomes. 


\section{Quadro 1: DADOS PESSOAIS E FORMAÇÃO - PROFESSORES, GESTORES E TÉCNICOS EDUCACIONAIS DE RECIFE3}

\begin{tabular}{|c|c|c|c|c|c|c|}
\hline $\begin{array}{l}\text { Professores } \\
\text { de ER }\end{array}$ & $\begin{array}{l}\text { Escolas } \\
\text { Visitadas }\end{array}$ & Idade & $\begin{array}{c}\text { Sexo/ } \\
\text { Orientação }\end{array}$ & $\begin{array}{l}\text { Formação } \\
\text { Acadêmica }\end{array}$ & $\begin{array}{l}\text { Tempo de } \\
\text { Trabalho }\end{array}$ & Religião \\
\hline PMR & $\begin{array}{l}\text { MUNICIPAL } \\
\text { RECIFE } 1\end{array}$ & 41 anos & $\begin{array}{l}\text { Feminino/ } \\
\text { Heterossexual }\end{array}$ & $\begin{array}{l}\text { Arte, Educação e } \\
\text { Administração }\end{array}$ & 02 anos & $\begin{array}{l}\text { Evangélica/ } \\
\text { praticante }\end{array}$ \\
\hline PMR & $\begin{array}{l}\text { MUNICIPAL } \\
\text { RECIFE } 2\end{array}$ & 39 anos & $\begin{array}{l}\text { Masculino/ } \\
\text { Heterossexual }\end{array}$ & História & o4 anos & Sem religião \\
\hline PER & $\begin{array}{l}\text { ESTADUAL } \\
\text { RECIFE } 1\end{array}$ & 36 anos & $\begin{array}{l}\text { Feminino/ } \\
\text { Homossexual }\end{array}$ & $\begin{array}{l}\text { História e } \\
\text { Teologia }\end{array}$ & 12 anos & Sem religião \\
\hline PER & $\begin{array}{l}\text { ESTADUAL } \\
\text { RECIFE } 2\end{array}$ & 40 anos & $\begin{array}{c}\text { Masculino/ } \\
\text { Heterossexual }\end{array}$ & $\begin{array}{l}\text { Língua } \\
\text { Portuguesa }\end{array}$ & 10 anos & $\begin{array}{l}\text { Católico/não } \\
\text { praticante }\end{array}$ \\
\hline GESTORES & Escola & Idade & $\begin{array}{c}\text { Sexo/ } \\
\text { Orientação }\end{array}$ & $\begin{array}{c}\text { Formação } \\
\text { Acadêmica } \\
\end{array}$ & $\begin{array}{l}\text { Tempo de } \\
\text { Trabalho } \\
\end{array}$ & Religião \\
\hline GMR & $\begin{array}{l}\text { MUNICIPAL } \\
\text { RECIFE } 1\end{array}$ & 57 anos & $\begin{array}{l}\text { Feminino/ } \\
\text { Heterossexual }\end{array}$ & $\begin{array}{l}\text { Língua } \\
\text { Portuguesa }\end{array}$ & 12 anos & $\begin{array}{l}\text { Evangélica/ } \\
\text { praticante }\end{array}$ \\
\hline GMR & $\begin{array}{l}\text { MUNICIPAL } \\
\text { RECIFE } 2\end{array}$ & 50 anos & $\begin{array}{c}\text { Masculino/ } \\
\text { Heterossexual }\end{array}$ & Geografia & o8 anos & Sem religião \\
\hline GER & $\begin{array}{l}\text { ESTADUAL } \\
\text { RECIFE } 1\end{array}$ & 45 anos & $\begin{array}{c}\text { Feminino/ } \\
\text { Heterossexual }\end{array}$ & $\begin{array}{c}\text { História } \\
\text { Especialização } \\
\text { Gestão Escolar }\end{array}$ & 02 anos & $\begin{array}{c}\text { Evangélica/ } \\
\text { não } \\
\text { praticante }\end{array}$ \\
\hline GER & $\begin{array}{l}\text { ESTADUAL } \\
\text { RECIFE } 2\end{array}$ & 53 anos & $\begin{array}{l}\text { Masculino/ } \\
\text { Heterossexual }\end{array}$ & $\begin{array}{l}\text { Língua } \\
\text { Portuguesa }\end{array}$ & 12 anos & $\begin{array}{l}\text { Evangélico/ } \\
\text { praticante }\end{array}$ \\
\hline $\begin{array}{c}\text { Técnicos } \\
\text { Educac. } \\
\text { Pernambuco } \\
\text { /Recife }\end{array}$ & Instituições & Idade & $\begin{array}{c}\text { Sexo/ } \\
\text { Orientação }\end{array}$ & $\begin{array}{l}\text { Formação } \\
\text { Acadêmica }\end{array}$ & $\begin{array}{l}\text { Tempo de } \\
\text { Trabalho }\end{array}$ & Religião \\
\hline TMR & $\begin{array}{c}\text { Prefeitura de } \\
\text { Recife/ Sec. } \\
\text { Municipal de } \\
\text { Recife }\end{array}$ & 46 anos & $\begin{array}{l}\text { Masculino/ } \\
\text { Homossexual }\end{array}$ & $\begin{array}{l}\text { Teologia e } \\
\text { Ciência das } \\
\text { Religiões }\end{array}$ & 16 anos & Sem religião \\
\hline TEP & $\begin{array}{l}\text { Sec.Estadual } \\
\text { de } \\
\text { Pernambuco/ } \\
\text { departamento } \\
\text { do Ensino } \\
\text { Fundamental I }\end{array}$ & 42 anos & $\begin{array}{c}\text { Feminino/ } \\
\text { Heterossexual }\end{array}$ & $\begin{array}{l}\text { Ciência das } \\
\text { Religiões }\end{array}$ & O5 anos & $\begin{array}{c}\text { Evangélica/p } \\
\text { raticante }\end{array}$ \\
\hline
\end{tabular}

Fonte: RELATÓRIO FINAL PIBIC/CNPq/UFPE. Recife, 2014.

\footnotetext{
3 PMR: Professora Municipal de Recife e PER: Professora Estadual de Recife. GMR: Gestora de Recife Municipal; GER: Gestora de Recife Estadual. TER: Técnico Estadual de Recife e TEP: Técnica do Estado de Pernambuco. Optou-se por não se colocar o nome das 04 escolas visitadas por pedido dos entrevistados (LIMA; OLIVEIRA, 2014).
} 
Como se pode observar pelo quadro, os colaboradores/parceiros da pesquisa (num total de 10 assim distribuídos: 02 professores de Ensino Religioso da Prefeitura Municipal de Recife, 02 professores de Ensino Religioso da rede estadual; 01 técnico da secretaria estadual e 01 técnico da secretaria municipal de Recife; 02 gestores de escola da rede municipal de Recife e 02 gestores de escola da rede estadual) situam-se até então, quanto à faixa etária, entre 36 e 57 anos. Em relação à escolaridade, são graduados principalmente em História e Língua Portuguesa. Quanto ao sexo e orientação sexual, cinco pessoas são do sexo feminino, sendo que quatro se assumem como heterossexuais e apenas uma se assume como homossexual e 05 são do sexo masculino, com um se assumindo como homossexual. Um campo interessante que os participantes se dispuseram a responder foi o da crença religiosa; este apresentou um pequeno percentual maior de evangélicos (05), concorrendo próximo aos sem religião (04) (LIMA; OLIVEIRA, 2014).

No que refere ao exame dos dados, pode-se afirmar que todos os entrevistados (técnicos educacionais, gestores escolares e professores) reconhecem que o ER se propõe a ser ensinado contemporaneamente de maneira não proselitista nas escolas e os professores, vão além, quando afirmam que ao lecionarem a disciplina, evitam tratar o currículo e os tema a ele relacionados com favorecimento de uma e/ou de certas religiões, em detrimento de outras (OLIVEIRA, 2013; LIMA; OLIVEIRA, 2014).

Esse reconhecimento em suas falas está atrelado aos documentos de base legal para esse tipo de ensino, ou seja, eles se apóiam na atual legislação educacional que versa sobre a disciplina, apresentando uma memória circulante que trata o discurso de um ER não proselitista como discurso hegemônico e legítimo. No entanto, estão presentes também em suas falas, discursos híbridos, relacionados a preceitos confessionais e religiosos, que reiteram lugares de submissão e opressão em relação às mulheres, principalmente, àquelas que fazem parte de segmentos socialmente e sexualmente estigmatizados. 
Essa afirmação evidencia-se na fala da seguinte gestora entrevistada quando diz “... o modo que acreditamos ensinar é interconfessional, porém, sabemos que em sala de aula o que vem prevalecendo ou prevaleceu por muitos anos foi o ensino das religiões cristãs e nessas as mulheres são submissas e marginalizadas, invisibilizadas" (GER). Outro exemplo dessa presença hibrida encontra-se no recorte da fala de outro gestor entrevistado:

Desde quando entrei já existia o Ensino Religioso. A escola já tinha desde a fundação, era um ensino diferente do de hoje. Antes era um ensino voltado para um tipo de religião muito puxado pra o católico apostólico romano, mas depois houve uma modificação, mas não sei dizer em que ano, mas, faz alguns anos (GMR).

A percepção de um ensino modificado faz parte de um conjunto de articulações que não envolve apenas o eixo de produção curricular, mas, um campo de negociações que se atrela à cultura enraizada e reinterpretada no espaço da dinâmica em sala de aula. Assim, faz-se necessário entender a construção de políticas curriculares, especificamente no caso do ER, com base não somente nos discursos dos documentos oficiais, mas também por meio das ressignificações de currículo feitas no espaço escolar (LIMA; OLIVEIRA, 2014).

A proposta curricular de ER em Pernambuco encontra-se em fase de elaboração, mas, o discurso que vem sendo difundido por professores dessa disciplina e nos documentos oficiais, já ressalta a importância deste ensino na formação básica do cidadão onde também, deverão ser assegurados: o respeito à diversidade cultural e religiosa do Brasil, não se aceitando quaisquer formas de proselitismo (INSTRUÇÃO NORMATIVA DE PERNAMBUCO $\mathrm{n}^{0}$ 01/2012/ SECRETARIA DE EDUCAÇÃO DO ESTADO DE PERNAMBUCO, acessado em 2013). O problema apresenta-se quando correlacionamos este discurso não proselitista, a temas de diversidades estigmatizadas como no caso da orientação sexual e das questões de gênero (OLIVEIRA, 2014). 
Sabe-se que a elaboração curricular apresenta lados que implicam em parcialidade e defesa de interesses. Sendo assim, o currículo evidencia relações políticas que envolvem dimensões culturais traduzidas pelos sujeitos através de sentidos circundantes presentes no campo da religião, ciência, crenças e valores. No caso das políticas curriculares, sublinha-se que elas passam por processos de recontextualização e hibridismo no qual se institui formas de se organizar o que é selecionado, tornando-o apto a ser ensinado (LOPES, 2006; LIMA; OLIVEIRA, 2014).

Portanto, é complexo o processo de tessitura de hegemonias curriculares, pois, as propostas são compostas de relações antagônicas pelos vários grupos sociais que insistem em querer ter acesso à formulação e ensino de disciplinas (OLIVEIRA, 2013). É necessário, desse modo, entender que a construção de políticas curriculares envolve ações que não se realizam sozinhas, à medida que estas fazem parte de um conjunto de negociações e posturas diversas (LOPES, 2006; LIMA; OLIVEIRA, 2014). Desta forma, no caso especifico de Pernambuco, a falta de um currículo institucionalizado tem dificultado o levantamento de pontos a serem discutidos e a percepção do antagonismo entre os vários grupos que disputam a hegemonia do ER no estado.

Neste sentido, é importante avaliar como a questão de gênero e sexualidade e/ou orientação sexual é tratada no currículo do ER porque tal avaliação pode fornecer elementos para se observar como essa disciplina lida com a diversidade e as várias identidades acionadas na atualidade e atreladas à concepção de cidadania e respeito às diferenças.

Neste aspecto, o que se observou, por meio dos discursos dos entrevistados, foram poucas falas apoiando a inserção da temática de gênero e sexualidade na disciplina do ER numa perspectiva de respeito e valorização das diferenças. A fala abaixo é raro exemplo de busca de bom trato na disciplina com a temática da diversidade sexual atrelada à questão da orientação sexual especificamente feminina: 
É um trabalho difícil, até mesmo, a valorização da mulher, por exemplo, a falta de respeito com as moças nas escolas; os garotos precisam entender que elas têm o poder de escolher com quem querem namorar, ficar; é preciso respeitar a mulher como ser humano independente da sua sexualidade. No trabalho com a disciplina de Ensino Religioso vejo isso, discuto como as várias religiões pensam as mulheres e também como são tratadas as orientações sexuais, mas não é fácil (PER).

Contudo, de modo hegemônico, em outros momentos identificam-se formações discursivas de medo e preconceito no trato especifico da homossexualidade feminina, vinculadas à ideologia heteronormativa e aos valores cristãos:

A temática é importante, mas difícil de ser trabalhada porque temos que reconhecer: a escola e o professor não tem suporte para lidar com a pressão dos familiares, e mais aqueles evangélicos, quando procuram a escola para reclamar dessa discussão. Homossexualidade, muitos deles tratam como pecado, coisa do demônio etc. e feminina, então. Isso nos preocupa muito até mesmo porque nós também temos nossos preconceitos religiosos, a maioria de nós é cristã e condena e dizer que não temos preconceitos seria uma mentira. Falar de desigualdade de gênero, especialmente nas aulas de Ensino Religioso é difícil, agora quando entra temas de homossexualidade fica muito pior (GMR).

As traduções e interpretações, adicionadas a equívocos e supergeneralizações quanto aos conceitos de gênero e sexualidade reforçam ainda mais essa ideologia heteronormativa e cristã dominante, à medida que são pautadas por discursos que não rejeitam o essencialismo sobre as identidades sexuais, defendendo que as mesmas sejam vivenciadas socialmente e culturalmente através das relações estabelecidas (LOURO, 2001):

Gênero é a natureza de ser humano, vem de Deus. É gênero que nasce já com o ser humano isso numa linguagem bem... [...] Eu não tô usando definições acadêmicas e nem termos técnicos. Já a sexualidade seria o impulso. O impulso do desejo ligado ao sexo. E uma coisa esta meio que ligada à outra, por que é a minha natureza ou gênero que nasce em mim junto com a sexualidade (PMR).

Não sei diferenciar. Sempre achei que sexo e gênero eram a mesma coisa e que a gente nasce com eles né, como fala a Bíblia? Embora ficava difícil de entender porque as vezes uma pessoa namorava com outra de sexo diferente e depois aparecia na escola com alguém do mesmo sexo. Nunca soube entender, explicar isso (PER). 
Diante disso, abaixo seguem as principais ideologias encontradas nas formações discursivas dos entrevistados envolvendo a temática:

a) Biológica-higienista - tal ideologia se apóia em concepções que reforçam lugares tidos como naturais entre homens e mulheres, pois, baseados na ideia de natureza (FURLANI, 2011): “... acho que muitos problemas poderiam ser resolvidos se cada um respeitasse cada um de acordo com sua natureza. Homem é homem e mulher é mulher, o respeito deveria começar daí” (TEP). Dessa forma, baseada no determinismo biológico, essa mentalidade entende as diferenças entres homens e mulheres a partir de atributos biológicos, colaborando com discursos machistas com formulações de premissas, sexistas, misóginas e homofóbicas (FURLANI, 2011).

b) Moral Tradicionalista - defensora de princípios como castidade pré-marital, por exemplo, condena a liberdade sexual contemporânea, reverenciando elementos de intervenção autoritários (FURLANI, 2011): “... hoje tá tudo liberado, daí essa ebulição sexual; na minha época não era assim, a gente tinha Educação Moral e Cívica que era boa porque ensinava a respeitar a ordem, não é como hoje" (TEP).

c) Terapêutica - faz uso do discurso da Psicologia para buscar causas e explicações das vivencias sexuais e "problemas sexuais" consideradas condutas "anormais” (FURLANI, 2011): “... talvez os psicólogos possam explicar os, as transexuais; me parece que esses são os casos mais complicados porque não aceitam sua condição de homem ou mulher de forma radical, ai acho que precisa de tratamento" (PMR).

d) Direitos Humanos - ideologia que objetiva problematizar e desconstruir representações negativas impostas socialmente a esses sujeitos e suas respectivas identidades excluídas (FURLANI, 2011): "Enquanto não respeitarmos as pessoas em suas diferenças, não construiremos uma sociedade 
melhor. Discutir na disciplina de Ensino Religioso a diversidade sexual e a questão de gênero é um passo importante para o desmonte de uma sociedade que ainda não entende que as desigualdades de gênero são criadas e que as religiões interferiram e continuam a interferir nisso. Enquanto não reconhecermos isso, fica difícil falar em Direitos Humanos e respeito ao outro" (TMR).

As ideologias citadas, a exceção da última de Direitos Humanos, foram as mais identificadas, no que se refere à disciplina de Ensino Religioso, articulada ao currículo e à temática de gênero e sexualidade. Elas não se apresentam de forma homogênea, mas sim caracterizadas pelo hibridismo, pois, nelas existem múltiplas maneiras de organização de seus enunciados e construção de determinados conhecimentos marcados por rupturas, divergências, discordâncias teóricas, políticas. (LIMA; OLIVEIRA, 2014).

\section{Considerações Finais}

A pesquisa em questão evidenciou que na área da educação, em escolas da rede municipal e estadual de Recife, tem se reconhecido, de modo hegemônico, que o ER se propõe contemporaneamente a ser ensinado de forma não proselitista, respeitando a diversidade religiosa, porém, quando seus sentidos e significados passam a expressar discursos que entrecruzam temáticas de gênero e sexualidade, as ideologias que se esboçam, em sua grande maioria, reiteram lugares de submissão e opressão em torno das mulheres, sobretudo as com orientação sexual marginalizada como lésbicas, bissexuais e transexuais. 
Percebe-se assim, que conteúdos que envolvem religião, gênero e sexualidade e que comumente se expressam no cotidiano das salas de aula, não são abordadas no ER dessas escolas públicas de Recife, principalmente, pela falta de um currículo específico que possa nortear atividades propostas para os alunos, levantando pontos a serem considerados e negociados ao redor destas temáticas. Diante disso, as dificuldades em se falar sobre a homossexualidade e diversidade sexual de modo geral, e de modo específico no caso feminino, são enormes.

Outra problemática relevante observada durante o trajeto da pesquisa disse respeito às traduções e interpretações feitas pelos profissionais que lecionam o ER sobre estes assuntos, muitas delas marcadas por posicionamentos vinculados ao receio da abordagem desses temas por medo de se enfrentar posições enraizadas socialmente e estigmatizantes em relação a mulheres lésbicas, bissexuais e transexuais, estas advindas hegemonicamente de orientações heteronormativas e cristãs, principalmente de cunho evangélico, e isso se aplicou inclusive ao caso dos sem religião, tendo em vista que dos 10 entrevistados, 04 declararam não possuir religião, todavia, desses 04, apenas os dois que se assumiram como homossexuais tiveram posições demarcadas discursiva e ideologicamente favoráveis a inserção da orientação sexual e/ou diversidade sexual e de gênero na disciplina em análise.

Adicionado a esse quadro, a falta de formação de professores para o ER impõe sérios e preocupantes obstáculos ao trato com esses conteúdos, dificultando o estabelecimento da prática da tolerância a qual, a própria disciplina se propõe a estimular no contexto da atual LBD de 1996. Destarte, ressalta-se a necessidade desse componente dialogar com um currículo pós-crítico, pós-estruturalista e pósfundacional, que entenda a sexualidade e/ou orientação sexual e o gênero como eixos visíveis e importantes de debate no campo do estudo do fenômeno religioso, provocando e promovendo esse encontro como forma de busca da alteridade no campo social/educacional. 


\section{REFERÊNCIAS}

ALVES, L; JUNQUEIRA, S. Educação Religiosa: construção da identidade do Ensino Religioso e da Pastoral Escolar. v.1, Curitiba: Champagnat, 2002.

BRASIL- Presidência da República.- Presidência da República. Plano nacional de políticas para as mulheres. Relatório de Implementação 2005. Brasília, maio de 2006.

BUTLER, J. Actos Performativos y Constituición del Gênero: un ensayo sobre fenomenologia y teoria feminista. Revista Debate Feminista, México, a. 9, v.18, 1998.

BUTLER, J. Corpos que Pesam: sobre os limites discursivos do "sexo". In: LOURO, Guacira Lopes. (org.). O Corpo Educado: pedagogias da sexualidade. 2.ed, Belo Horizonte: Autêntica, 1999.

BUTLER, J. Desdiagnosticando o Gênero. Physis Revista de Saúde Coletiva, Rio de Janeiro, n.1, v. 19, 2009.

CARDOSO, C. M. Tolerância e seus Limites: um olhar latino-americano sobre diversidade e desigualdade. São Paulo: Editora UNESP, 2003.

CAULFIELD, S. Em Defesa da Honra: moralidade, modernidade e nação no Rio de Janeiro (1918-1940). Campinas, SP: Editora da Unicamp, 2000.

ENDSJO, D. O. Sexo e Religião: do baile de virgens ao sexo sagrado homossexual. São Paulo: Geração Editorial, 2014.

ENGEL, M. Meretrizes e Doutores: saber médico e prostituição no Rio de Janeiro (1840-1890). São Paulo: Editora Brasiliense, 2004.

FURLANI, J. Educação Sexual na Sala de Aula: relações de gênero, orientação sexual e igualdade étnico-racial numa proposta de respeito às diferenças. Belo Horizonte:

Autentica, 2011.

GRUPO DE PESQUISA EDUCAÇÃO E RELIGIÃO (GPER). Disponível em:<http://www.gper.com.br/>. Acessado em: 02 fev. 2015.

GOFFMAN, E. Estigma: notas sobre a manipulação da identidade deteriorada. 4 ed, Rio de Janeiro: Editora Guanabara, 1988.

IBGE, 2000. Disponível em:

<http://www.ibge.gov.br/home/estatistica/populacao/censo200o/>. Acessado em 2013.

IZUMINO, W. P. Justiça e Violência Contra a Mulher: o papel do sistema judiciário na solução dos conflitos de gênero. São Paulo: Annablume, 1998. 
LACLAU, E. ; MOUFFE, C. Hegemony and Socialist Strategy: towards a Radical Democratic Politics. London: Verso, 1985.

LIMA, R. da S; OLIVEIRA, A. M. de. Pluralismo, Alteridade e Relações de Gênero: problematizando o debate nas escolas estaduais e municipais de Recife acerca do lugar que a mulher ocupa no currículo da disciplina de Ensino Religioso. [Relatório final de atividades do aluno de iniciação científica (ic) Pibic/UFPE/CNPq ago. 2013 a jul. 2014].

LOPES, A. C. Discursos nas Políticas de Currículo. Currículo sem Fronteiras, v.6, n.2, p.33-52, jul./dez., 2006.

LOPES, A. C. Políticas Curriculares: continuidade ou mudança de rumos? Revista Brasileira de Educação, Rio de Janeiro, n. 26, 2004.

LOURO, G.L. Teoria Queer - uma política pós-identitária para a educação. Estudos Feministas, Florianópolis, v.9, n.2, p. 541-553, 2001.

OLIVEIRA, A. M. de. Multiculturalismo, Pluralismo e (In) Tolerância Religiosa: o relacionamento dos espíritas pernambucanos com os adeptos de outras religiões (19902004), 2006, 353f. Tese (doutorado em Sociologia) - UFPE, Recife.

OLIVEIRA, A. M. Preconceito, Estigma e Intolerância Religiosa: a prática da tolerância em sociedades plurais e em Estados multiculturais. Estudos de Sociologia, Recife, v. 13, n. 1, p. 239-264, 2007.

OLIVEIRA, A. M. de ; SILVA, D. E. da. Alteridade x Intolerância: diretrizes curriculares que podem embasar mais democrática e pluralmente o Ensino Religioso. Revista Teias, Rio de Janeiro, v. 13, n. 27, p. 139-160, jan./abr. 2012.

OLIVEIRA, A. M. Currículo, Alteridade e Tolerância no Campo do Ensino Religioso: uma análise através das categorias de hegemonia e agonismo. $\mathbf{3 6}^{\mathbf{a}}$ Reunião Nacional da Associação Nacional de Pós-Graduação e Pesquisa em Educação (ANPED). Goiânia, 2013a.

OLIVEIRA, A. M., ANDRADE JR.; P. M., REZENDE, D. S. ; RIBEIRO, J. E. N. Ensino Religioso no Brasil: comparando as experiências de Sergipe e Pernambuco numa perspectiva de construção da tolerância. Reflexão e Ação (Online), Santa Cruz do Sul, v.21, n.1, p.49-70, 2013b.

OLIVEIRA, A. M. Pluralismo e Alteridade: o lugar que os segmentos LGBTTTI ocupam no currículo da disciplina de Ensino Religioso nas escolas estaduais e municipais de Recife (PE). Revista Pistis \& Práxis, Curitiba, v. 6, n.2, p. 611-625, 2014.

ONG GRUPO LEÔES DO NORTE. Disponível em:< http://leoesdonorte.tumblr.com/>. Acesso em 30/03/2014.

ORLANDI, E. P. Análise de Discurso: princípios e procedimentos. Campinas, SP: Pontes, 2002. 
PORTELLA, A. P. Rotas de Exclusão. Recife: SOS Corpo, 2003.

PRESTRELLO, C. (coord.). Turismo Sexual, Tráfico, Imigração: o que temos nós a ver com isso? Recife: Coletivo Mulher Vida, 2003.

SECRETARIA DE EDUCAÇÃO DO ESTADO DE PERNAMBUCO. INSTRUÇÃO

NORMATIVA/ESTADO DE PERNAMBUCO nº 01/2012. Disponível em

http://www.educacao.pr.gov.br/arquivos/File/instrucoes/instrucaonormativa012012grhs. pdf. Acessado em 2013.

SOS CORPO - Instituto Feminista para a Democracia. Disponível em http://soscorpo.org/. Acesso em 2012.

SOS CORPO - Instituto Feminista para a Democracia. Pesquisa. Disponível em http://soscorpo.org/areas-de-trabalho/pesquisa/. Acessado em 28/02/2014.

WOLFF, P. R.; BARRINGTON, M. JR. ; MARCUSE, H. Crítica da Tolerância Pura. Rio de Janeiro: Zahar Editores, 1970. 